\title{
Challenges of sustainable and equal development of regions in Georgia
}

\author{
Badri Gechbaia ${ }^{1,{ }^{*}, \text { Eteri } \text { Kharaishvili }^{2}, \text { Zurab Mushkudiani }}{ }^{3}$, Ketevan Goletiani $^{3}$, and Amiran Tsilosani $^{1}$ \\ ${ }^{1}$ Batumi Shota Rustaveli State University, Georgia \\ ${ }^{2}$ Ivane Javakhishvili Tbilisi State University, Georgia \\ ${ }^{3}$ Batumi Navigation Teaching University, Georgia
}

\begin{abstract}
In the present paper is analysed opinions about the tools for sustainable development and the ways to reduce inequality. Has been estimated the importance of regional development programs and strategies as the settlement of the economic and social issues, provided proof of their role in the effective development of regional economic policy. Has been determined the concentration level of economic activity by regions using distribution index to estimate equal development of regions. Has been made the conclusion that none of the regions of Georgia is notably specialized. The concentration level of business sectors in regions is substantiated by the distribution curve. In distribution curve was considered retail and wholesale distribution, as an example of maximally near to ideal distribution. It is proved by the analysis of distribution of curves, that the concentration level of business sectors in Georgian regions is quite unequal and none of them could be highlighted in industry specialization. The paper identifies the problems related to sustainable and equal development of regions, provided conclusions and recommendations to settle the mentioned issue by their estimation. In the process of study has been determined the factors of endogenous development of regions and advisable to improve the quality and efficiency of regional development institutions through the development of trial-programs for regional development.
\end{abstract}

\section{Problem statement}

Historically Georgia is a country with a regional system. The regional structures are adapted to the economic, social, cultural, ethnic, and other factors. According to the above-mentioned, there are 12 historical-statistical regions in the country. At the same time, Georgia is distinguished by many difficulties in terms of regional arrangement and a high level of inequality between the regions. Even more, inequality is visible not only between the regions but between municipalities within the regions. The regions differ from each other by areas, population, potential of natural resources, economic development, demographic specifics, social spheres, investment environment, traditions, and other signs.

Sustainable and equal development of regions is a relevant issue for researchers. The unusual difficulties and obstacles are characterized by the developing events in the modern world. At the same time, global economic development, including the economic situation of any country, is assessed based on aggregated data of its constituent and carried out planning of efficient regional policy. The effectiveness of the policy depends on a deep analysis of the object's spatial-territorial characteristics of the policy itself and the usage of sustainable and equitable development mechanisms of regions.

The Association Agreement between Georgia and the European Union obliges Georgia to emphasize and focus on the development of poor regions and territorial cooperation in the field of regional policy [1]. The attempt to develop poor territorial units and achieve equality between the regions may cause a step back from the potential development of economic growth for developing countries. Therefore, the questions to be answered are the following: What factors lead to unequal development of regions? What causes the high and constant level of social inequality between the regions? What mechanisms could be used for equal development of the regions? What factors are the main drivers for the sustainable development of the regions? To answer the questions above, it is needed to provide research.

Recommendations developed based on the research will support in mid-terms the implementation of integrated territorial measures in Georgia, achievement of regional development policy goals, increase competitiveness of the regions, balanced social-economic development and improvement of living conditions in the regions, improvement of infrastructure for support of sustainable development, support particular territories and identify endogenic factors of development, increase the quality and efficiency of regional institutions, development of trial-programs for regional development.

On the assumption of relevance of the issue, we have aimed to identify the challenges of the regions of Georgia in sustain and equal development and elaborate recommendations of its solution.

\footnotetext{
* Corresponding author: gechbaia.badri@bsu.edu.ge
} 


\section{Research methods}

In the process of research has been used methods of analysis, synthesis, and comparison.

The analysis of the documents of the strategy has been made using a comparison model. For achieving the goal and objectives of the study has been conducted desk survey. The existing theoretical and methodological approaches related to issues have been studied through reports, researches, and scientific articles. During the study, statistical calculations were carried out based on official sources (World Bank, Eurostat, Faostat, Geostat, and other); The primary materials necessary for publication were obtained from the National Statistical Office, the Ministry of Economy and Sustainable Development, the Ministry of Environment and Agriculture, the Ministry of Regional Development and Infrastructure of Georgia and various agencies.

For enhanced interviews and focus groups, various guides and questionnaires were developed, depending on the content of each task. The latter relied on information obtained as a result of desk research. The respondents in the research process were: representatives of local and international non-governmental organizations working on regional development issues, professors and researchers from universities and other research institutions; Representatives of the Ministry of Regional Development and Infrastructure and other government agencies; Industry experts, locals, and the representative of the business sector.

To determine the concentration of business activity and level of equal development in the regions has been used different indexes, including distribution and specialization indexes. Also has been used qualitative research tools (semi-structured interviews and meetings with focus groups).

\section{Literature review}

Finding tools for sustainable development in the regions and ways to reduce inequality is an important area of research in the scientific community nowadays. Sustainable development is in connection with the identification of territorial inequality issues. In this regard, the researchers analysing relevant issues of sustainable development and territorial fairness of the regions [2].

Currently, regions of the world are actively participating in the planning of sustainability with the following three main components: environment, economics, and capital. At the same time, researchers proposed ways to solve the issue related to the inequality development of the regions [3].

In European countries, it is especially important to study sustainable development issues of the regions from the perspective of sustainable resource management and fairness of social security. The researches in this field support and contribute to the formation of an equal society. In this regard, by studying different stages of regional development of Slovenia, researchers identified the connection between sustainable development of the region and health inequality overcoming [4].

Commonly, the concept of sustainable development of the regions is reflected integrated development of society (social, economic, and environmental protective). This type of conception is the basis of sustainable development of the regions in European countries. Scientists have analysed those tools, which are supporting the sustainable development of the regions in economic initiative framework, consequently scientists proposing the ways of sustainable development of the regions [5].

To achieve sustainable regional development and reduce regional inequality, it is important to elaborate on respective programs and strategies. Such programs and strategies are assessed by researchers based on economic and social issues, justified their role in elaboration of effective regional economic policy, identified the differences by location, culture, and other factors [6].

Sometimes, equality between the regions, in developing countries, is achieved through economic development. Frequently issue of disputes becomes on how effective-oriented regional policy supports the distribution of wealth between the regions and vice versa, could it be that equality becomes the main reason for ineffectiveness [7].

Scientists investigate the forms of relationships between the constituent parts of the region for the sustainable development of regions. The movement of a product, labour, or capital within a region may be random and may not indicate a specific direction of flow. [8]. The research literature also provides slightly different views on the definition of a functional region [9].

The main criteria to identify a functional region is the level of its isolation from other regions. The movement of product, labour, or capital not necessary to be explicitly organized within a functional region [10]. Worth mentioning that the regions make a significant contribution to the development of the process of manufacturing diversification in terms of social and cultural heritage, especially in mountainous regions [11].

The scientific papers include discussions on theoretical and empirical issues of economic growth in the regions, researches of the conceptual basics of economic growth, assessments of the paradigms, and trends of the regional development. At the assessing stage of the regional economic policy are discussed issues related to the difference in per capita income, also is sustained the role of areal structure in the formation of the labour market.

Research of equitable development of regions is especially relevant from the density of population and enterprises study prospective. The concentration of population and businesses obviously depends on land price, its characteristics, and constraints. In the case of Georgia, based on these factors, the issue requires deeper research.

However, in the field of spatial economics, should be made the following conclusions: land prices are more expensive the closer the sales market is, costs of housing and relocation increases the bigger the city size is, which reduces the real income of the population. The latter is the main reason why part of the population not willing to live 
in big cities [12]. We can say that only in a few cities of Georgia are the tendency of cost increase in terms of housing and relocation. Most cities are still less attractive to the citizens and businesses. Consequently, the price of land is relatively low, which allows the creation of centres and achieve high rates of agglomeration.

Nowadays, even more effective planning of regional development policy is a significant challenge for many countries worldwide. The goals of regional "equality" and "efficiency" are the main issues of discussion among the researchers in the field of regional policy. The subject of research and controversy is whether a regional policy guided towards efficiency contributes to an equal distribution of wealth among regions or vice versa, whether an approach guided towards equality can be the cause of inefficiency [13].

The goal of efficiency is to maximize the growth of the national economy and the optimal allocation of resources over time, while the goal of equality focuses on reducing unequal levels of income, wealth, and economic growth between regions. In certain cases, these goals could be compatible, but the significance of unequal development in regions requires the policy providers to focus on one main goal. Therefore, regardless of the choice of policy providers, the necessity to study the factors causing inequality is unavoidable. At the same time, it is necessary to make a benefit and cost analysis that will be obtained as a result of changing the economic growth direction with government intervention.

The effectiveness of regional structures in Georgia in terms of economic development policy objectives has not been studied. Evaluation criteria are accordingly not defined. Research is also complicated by the fact that the regional level of government is not defined by law, but historical districts/regions are subject to policy planning [14].

\section{Results of research}

The transformation of the economy of Georgia influenced the strategy of regional development, which takes into consideration the solution of their economic, social, and environmental issues. Georgia has certain guidelines for the sustainable development of the regions, for the expansion of regional markets [15]. Strategies and programs for the development of the regions of Georgia were developed. Based on analysis of these documents and the primary data received from the persons who were participated in the elaboration of the aforementioned documents, has been identified that mostly, documents include descriptive data about the regions [16].

However, should be mentioned that Georgia announced its readiness with the other countries of the UN to achieve sustainable development aims and targets by 2030 [17].

Mountainous regions have a key role in the socioeconomic development of Georgia. Accordingly, based on an analysis of the socio-economic situation and existing potential, the Strategy for the Development of Mountain Settlements of Georgia presents a strategic vision for the inclusive and sustainable development of regions with an emphasis on the need for equal socioeconomic development of the regions [17].

It is very important to determine the levels of governmental bodies for sustainable and equal development of the regions. As of now, Georgia considers four-level government: central, regional, district, and municipal. In terms of institutional and functional aspects, from the named levels, mostly developed the first level.

The second one, the regional level, is determined by historical, cultural, geographical, economic, ethnic, and other signs, and such a division has preserved the centuries. At the same time, it is significant to create steady food manufacturing conditions in the regions. Regional features still firmly bare in minds of the population. The process of regionalization still is irreversible, and it is effective to manage the country and stabilize economic conditions through the regional institutions [18; 19] and optimizing knowledge [26]. However, at the regional level institutional structures, undeveloped infrastructure, cluster relations $[20 ; 21]$ are weak, there are no conditions for sustainable development, and the difference in wealth fare indexes between the regions is obvious.

By territories largest region is almost 5.6 times bigger than the smallest one. By population of the smallest region as compared to the largest is almost 17 times less [23]. There is a deficiency of urban-type mid-size territories in the country, which causes social-economic inequality between the regions.

By combining assessments of various approaches, theories, and models of sustainable and equitable regional development, we have identified the main characteristics of the regions of Georgia:

- regions are characterized by economic similarity; there are some central places, so-called "Centers of gravity";

- natural resources, ecosystems, or other geographic features within a region are similar;

- the regions are characterized by similar impacts under the influence of various external and internal factors;

- each region includes a small number of high demand settlements and a large number of low demand settlements and it is characterized by manageability.

The grouping of settlements in the regional context showed that the number of different types of settlements is quite asymmetric, moreover the spatial difference in consumer demand between urban settlements, and rural settlements is huge and the regions do not correspond to this index of inequality (see Table 1).

The distribution of GDP across regions is also asymmetric (see Figure 1).

Relatively high GDP is reflected in regions with selfgoverning cities and industrialized zones. For example, the Autonomous Republic of Adjara, Kvemo Kartli, and Imereti in Georgia. The indicators are especially low in the regions of Guria, Samtskhe-Javakheti, MtskhetaMtianeti, Racha-Lechkhumi and Kvemo Svaneti in Georgia.

The growth rate of the GDP of Georgia was $5.1 \%$ in 2019 [20]. During the pandemic, there are expectations that this indicator will keep decreasing, according to 
experts, mostly vulnerable and impacted sector will be tourism, which will lead to more inequality between the regions [20].

Table 1. Grouping of settlements by number (pcs.) and average population (people) by regions

\begin{tabular}{|c|c|c|c|c|c|c|c|}
\hline Regions & $\begin{array}{c}\text { Number of } \\
\text { cities }\end{array}$ & $\begin{array}{c}\text { Average } \\
\text { population } \\
\text { living in } 1 \\
\text { city } \\
\end{array}$ & $\begin{array}{c}\text { number of } \\
\text { towns }\end{array}$ & \begin{tabular}{|c|} 
Average \\
population \\
living in 1 \\
town \\
\end{tabular} & $\begin{array}{c}\text { number of } \\
\text { villages }\end{array}$ & \begin{tabular}{|c|} 
Average \\
population \\
living in 1 \\
village \\
\end{tabular} & \begin{tabular}{|l|} 
Spatial difference \\
in consumer \\
demand in urban \\
settlements from \\
rural settlements
\end{tabular} \\
\hline $\begin{array}{c}\text { Autonomous } \\
\text { Republic of Adjara } \\
\end{array}$ & 2 & 84,693 & 5 & 3,078 & 322 & 463 & 189 \\
\hline Guria & 2 & 10,590 & 5 & 2,145 & 186 & 438 & 29 \\
\hline Imereti & 11 & 23,168 & 2 & 1,834 & 535 & 515 & 49 \\
\hline Kakheti & 9 & 7,947 & 0 & - & 333 & 742 & 11 \\
\hline Mtskheta-Mtianeti & 2 & 7,054 & 5 & 1,430 & 480 & 153 & 56 \\
\hline $\begin{array}{l}\text { Racha-Lechkhumi } \\
\text { and Kvemo Svaneti }\end{array}$ & 3 & 2,008 & 2 & 474 & 251 & 100 & 25 \\
\hline $\begin{array}{c}\text { Samegrelo-Zemo } \\
\text { Svaneti }\end{array}$ & 8 & 15,535 & 2 & 2,557 & 521 & 387 & 47 \\
\hline $\begin{array}{c}\text { Samtskhe- } \\
\text { Javakheti }\end{array}$ & 5 & 9,107 & 7 & 1,304 & 259 & 409 & 25 \\
\hline Kvemo Kartli & 7 & 24,731 & 5 & 1,401 & 351 & 695 & 38 \\
\hline Shida Kartli & 4 & 23,589 & 2 & 5,428 & 373 & 424 & 68 \\
\hline
\end{tabular}

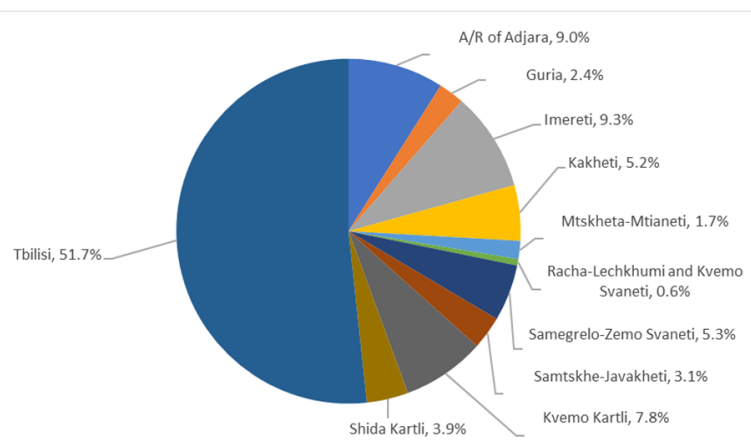

Fig. 1. Regional structure of GDP of Georgia [17; 23]

Significant inequality in GDP for the regions of Georgia was observed even before the pandemic: GDP per capita hovers 2.7 times between the richest and poorest regions. Tbilisi has the largest share in the country's GDP (49\%) [20]. In addition, $72 \%$ of the total turnover of the business sectors comes from companies operating in Tbilisi. This index is 2.5 times more than other company's index operating in other regions of Georgia. Georgian economy is quite diversified by its structure, but the economy of Tbilisi is more competitive. $86 \%$ of foreign direct investments come to the Tbilisi region of Georgia. Meanwhile, there is a decrease tendency of foreign direct investments in most of the regions of Georgia, such as Guria, Racha-Lechkhumi and Kvemo Svaneti, Shida Kartli, and Mtskheta-Mtianeti [16; $17 ; 20]$. This kind of concentration of the economy is the biggest challenge for Georgia and its regions.

The study of the needs and potential of regional development showed that Georgia, on the one hand, has many challenges for further development, and on the other hand, has significant potential that can be effectively used for deepening of economic development and improvement of the quality of life of its citizens.

To find the ways of equal development of the regions it is vital to know what concentration of economic activity in the regions is.

We have measured the concentration of specific sectors in the regions by using a distribution index, took into consideration regional inequality characterized by the small countries [24]. Analysis of the results showed that none of the regions is notably specialized.

Among the relatively concentrated types of economic activity in the regions, there is only agriculture, forestry, and fish farming, as well as the mining industry, and quarrying. In this regard, the regions of RachaLechkhumi, Samegrelo-Zemo Svaneti and Kvemo Kartli stand out. In terms of mining and quarrying, this sector is especially concentrated in the Kvemo Kartli and Imereti regions.

The level of concentration of business sectors in the regions has been precise by distribution curves [20;25]. In time of making distribution curves has been considered that retail and wholesale is as an example of maximally near to ideal distribution. In this case, involvement in business sectors from the regions is proportionally equal. The deviation from this curve reflects a high concentration in one or more regions (see Figure 2).

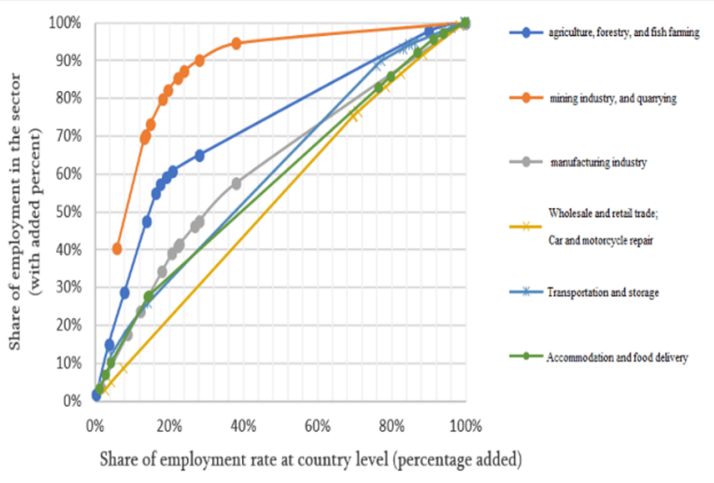

Fig. 2. Distribution curve by regions of Georgia by five sectors [20]

The distribution of the curves also affirmed that the level of concentration of business sectors in the regions of Georgia is rather unequal. This means that none of the regions are distinguished by industry specialization, only a relatively high specialization observed in the Kvemo Kartli region, the merit of which is existing natural resources and "support" on the issuance of permissions for their extraction.

\section{Conclusion}

Consequently, for the sustainable and equitable development of regions in Georgia, for the effective functioning of the regions is needed strong correlation between the components of the population, the business sector, and the territory. The above mentioned will create and strengthen regional relations, interdependencies, create conditions for sustainable development and a basis for a relatively equal concentration of economic activity.

Based on the results of the study, the following conclusions and recommendations were made: - indicators of economic activity in the regions of Georgia are very different from each other. These figures are affected by the decision of the population and the business sector about their place of residence, work, and sphere of economic activity. Consequently, the possibilities for sustainable development of regions 
should be determined not by the principle of territorial similarity, but by the spatial characteristics of territorial units;

- $\quad$ one of the obstacles to the possible benefits of spatial concentration and economic agglomeration is the land price. Most cities in Georgia are less attractive for the population and business, therefore the price of land is relatively low. At this stage of development, low land prices will create an opportunity to create centers and achieve a high speed of the agglomeration process;

- the analysis of distribution indexes by the regions of Georgia showed that the concentration of sectors is not typical for none of the regions, and economic activity between regions is diversified. To increase the concentration and rapid development of the municipality recommended the following: to organize the infrastructure with a focus on the centers of the municipality; Develop and expand ties between municipalities; Create appropriate infrastructure connecting territorial units around municipal centers; facilitate migration to settlements if needed, etc.

In planning regional policy, it is necessary to choose between the goals of "equality" and "efficiency". Should be noted that the EU's "rapprochement" policy is more focused on achieving the goal of "equality". By the policy of rapprochement with the EU, reducing inequality between regions should be the high priority of Georgia's strategic goals.

Unequal development and weak territorial ties are obvious between the regions of Georgia. It is necessary to establish and develop functional interdependencies between territorial units. Especially, should be improved links between regional centres and the capital city.

The following approaches should be used to identify opportunities for equal development in the regions: a clear focus on efficiency; Concentration of economic activity as a strong side of regional development; Replacing the sectoral approach with a multi-sectoral policy, focused on territorial development; Promotion of specialization, clustering, etc.

The analysis of growth opportunities of the regions of Georgia has proved that the perspective of rapprochement and equal development is more short-term for those regions which have economic centers. In case the regions do not have strong centers, it is recommended that regional policy was initially focused on the creation and development of such centers.

The analysis of the existing four-level government in Georgia (central, regional, district, and municipal) has been proved, that the regionalization process is irreversible nowadays and that is possible to achieve equal and sustainable economic development through regional institutions; lack of mid-sized urban areas aggravates further inequality problem.

Comparison of territorial, demographic, economic, social and other factors of the regions of Georgia showed that there is harsh inequality between social-economic development levels between the regions.

The Study of the needs and potential of regional development showed that Georgia, on the one hand, has many challenges for further sustainable and equal development, and on the other hand, has significant potential to improve economic development and quality of life of its citizens.

\section{References}

1. Association Agreement EU-Georgia (2014), https://eur-lex.europa.eu/

2. B. Zuindeau, Environmental Values J., 16, 253-268, (2007)

3. K. Chapple, Planning Sustainable Cities and Regions/Towards More Equitable Development (Routledge, 2015)

4. WHO, Sustainable development in Wales and other regions in Europe - achieving health and equity for present and future generations, 37, (2017)

5. R. Jovovic, M. Draskovic, M.Delibasic, M. Jovovic, JOIS J., 10, 259, (2017)

6. A.A.Davidescu, S.A.Apostu, A.M.Pantilie, B.F.Amzuica, MDPI Sustainability J., 18, 138, (2020)

7. J. Dawkins, Journal of Planning J., 18(2), 131-172 (2003)

8. M., Erlebach, P. Klapka, M. Halás, P. Tonev, Inner structure of functional region: theoretical aspects. In 17th International Colloquim on Regional Science. Conference Proceedings, Hustopeče 18-20 June 2014

9. M. Erlebach, M. Tomáš, P. Tonev, A functional interaction approach to the definition of meso regions: The case of the Czech Republic. Moravian Geographical Reports 24(2), 37-46 (2016)

10. P. Klapka, M. Halás, P. Tonev, Functional regions: concept and types. 16th International Colloquium on Regional Sciences. Conference Proceedings, Brno 19-21 June 2013, https://doi.org/10.5817/CZ.MUNI.P210-6257-201311

11. R. Neudert, N. Allahverdiyeva, N. Mammadov, A. Didebulidze, V. Beckmann, Diversification of Livestock-Keeping Smallholders in Mountainous Rural Regions of Azerbaijan and Georgia, Land 9(8), 267. (2020).

12. M. Fujita, J. F. Thisse, Economics of agglomeration. Journal of the Japanese and international economies, 10(4), 339-378.

13. O. Hutsaliuk, V. Koval, O. Tsimoshynska, M. Koval, H. Skyba, Risk Management of Forming Enterprises Integration Corporate Strategy. TEM Journal 9(4), 1514-1523 (2020)

14. M. Jibuti, Administrative Division, Regions of Georgia and their Characteristics. Globalization And Business 8, 126-129 (2019)

15. E. Karaishvili, B. Gechbaia, G. Mamuladze, Innovative Marketing J. 14, 8-16, (2018)

16. Regional Development Programme Of Georgia 2018-2021 (2018), https://mrdi.gov.ge 
17. Agenda 2030: 17 Goals For Sustainable Development (2015), https://sdgs.un.org/ru/goals

18. K. Kostetska, N. Khumarova, Umanska, Y., N. Shmygol, V. Koval, Institutional qualities of inclusive environmental management in sustainable economic development. Management Systems in Production Engineering 28 (2), 15-22 (2020)

19. I.W.E.Arsawan, V.Koval, I. Rajiani, N.W. Rustiarini, W.G. Supartha, N.P.S. Suryantini, Leveraging knowledge sharing and innovation culture into SMEs sustainable competitive advantage. International Journal of Productivity and Performance Management, (2020 in press) https://doi.org/10.1108/JJPPM-04-2020-0192

20. National Statistics Office of Georgia: Regional Development (2020), https://www.geostat.ge/en

21. N. Shmygol, F. Schiavone, O. Trokhymets, D. Pawliszczy, V. Koval, R. Zavgorodniy, A. Vorfolomeiev, Model for assessing and implementing resource-efficient strategy of industry. CEUR Workshop Proceedings 2713, 277-294 (2020)

22. V.Koval, I. Mikhno, O. Trokhymets, L. Kustrich, N.Vdovenko, Modeling the interaction between environment and the economy considering the impact on ecosystem. E3S Web Conf. 166, 13002 (2020)

23. EPRC, Economic consequences for the world and Georgia (2020), https://eprc.ge/

24. C. J. Dawkins, Regional development theory: conceptual foundations, classic works, and recent developments. Journal of planning literature 18(2), 131-172 (2003)

25. B. A. Portnov, D. Felsenstein, Measures of regional inequality for small countries (Springer, Berlin, Heidelberg, 2005)

26. I. Arsawan, I. Wayan Wirga, Ismi Rajiani, Ni Putu Santi Suryantini, Harnessing knowledge sharing practice to enhance innovative work behavior: the paradox of social exchange theory, Polish Journal of Management Studies 21(2), 60-73 (2020). 